\title{
RELATIONSHIP BETWEEN FATIGUE AND FUNCTIONAL STATUS OF THE ELDERLY PATIENTS ON HEMODIALYSIS Mohamed Ali Abd-Rabouh ${ }^{1}$, Soad Hassan Abd Elhameed ${ }^{2}$, Amany Mohamed Shebl ${ }^{3}$ \\ ${ }^{I}$ Nurse specialist at New Mansoura General Hospital, Mansoura city, Egypt ${ }^{2}$ Associate professor of Gerontological Nursing, Faculty of Nursing, Mansoura University, Egypt \\ ${ }^{3}$ Professor doctor of Medical Surgical Nursing, Faculty of Nursing, Mansoura University, Egypt
}

\begin{abstract}
:
Hemodialysis is a physically stressful procedure and most of the elderly patients will have fatigue. Fatigue is a common and debilitating symptom, affecting $42-89 \%$ of endstage kidney disease patients. It is a complex, multidimensional, and multifactorial phenomenon with huge repercussions on functioning, quality of life and elderly patient outcomes. Aim: determine the relationship between fatigue and functional status of the elderly patients on hemodialysis. Method: A descriptive co-relational design was used. Setting: This study was carried out at the hemodialysis unit at New Mansoura General Hospital in Mansoura city affiliated to the Ministry of Health. Tools: Data was collected using 4 tools, Tool I : Structured interview questionnaire sheet, Tool II: Katz and Akpom scale , Tool III: Lawton and Brady scale, Tool IV: Multidimensional Fatigue Inventory Scale (MFI-20).Results: the study revealed that about half of the studied elderly (51.8\%) have high level of fatigue and there is a significant correlation between fatigue and the functional status of the elderly patients on hemodialysis. Conclusion \& recommendation: The frequency of fatigue is high among hemodialysis patients. Fatigue has an effect on the functional status of hemodialysis elderly patients. Development \& Implementation of Health educational programs for newly elders on hemodialysis about hemodialysis process and fatigue and its management.
\end{abstract}

Key words: Fatigue, Functional status, Elderly, Hemodialysis.

\section{Introduction:}

A rapidly aging population has been observed worldwide, from 461 million people older than 65 years in 2004 to an expected 2 billion people by 2050 (Clegg et al., 2013).Aging directly has an effect on the prevalence of chronic diseases including: cognitive impairment, cancer; DM; osteoporosis; the need for prosthetic hip and knee replacements; the demand for long-term care and prescription therapy; urological diseases; and chronic renal disease (Levey et al., 2009).Populations studies worldwide have repetitively shown a positive association between increased age and the prevalence of chronic kidney disease (Zhang et al., 2012).

Still more significantly, the elderly create a substantial and continuously rising fraction of the end-stage renal disease population in the USA and other industrialized nations. According to the US Renal Data System, 25\% of patients beginning dialysis are over the age of 75 years (Collins et al., 2008) and older patients now signify the fastest growing group on dialysis (Holley, 2011). Moreover, older patients typically grieve from a larger number of co- morbidities such as cardiovascular diseases, osteoarthritis, cognitive impairment, 
osteoporosis and cancer - in comparison with younger patients (Stevens et al., 2010). With aging, non-communicable diseases such as hypertension (HTN) and diabetes mellitus (DM) have become more widespread. Therefore, the need for renal replacement therapy (RRT) has grown among elderly patients, as HTN and DM are the leading reasons of chronic renal disease (Kurella et al., 2007).

Chronic kidney disease (CKD) is a global public health problem with an growing prevalence (Ozcan and Ulsoy, 2011). Cardiovascular disease (CVD) and infections are the main sources for the increased occurrence of morbidity and mortality among elderly patients with CKD (Cohen and Horl, 2012). Progression of $\mathrm{CKD}$ is associated with a number of serious complications, containing cardiovascular, metabolic and endocrinal conditions (Thomas et al., 2008).

The last stage of chronic kidney disease is end stage renal disease (ESRD) that arises when the glomerular filtration rate (GFR) is under $15 \mathrm{ml} / \mathrm{min}$ (Headley, 2011). End stage renal disease is an irreversible progressive kidney disorder that removes the body power for balancing liquids and electrolytes and causes uremia and azotemia (Mottahedian et al.,2009). The standard management of ESRD is either dialysis or kidney transplantation (Larson et al., 2013).

The average age for incidence is now about 65 years old (Shaker, 2015). In Egypt, the estimated annual incidence of ESRD is around 74 per million (Ahmed ,2010) and the total prevalence of ESRD is 650 per million (Barsoum, 2013). The number of patients being cured for ESRD all over the world was 3,200,000 at the end of 2013, and with a 6\% growth rate. Approximately 2,522,000 were undergoing dialysis treatment (hemodialysis) [HD] and peritoneal dialysis [PD] of these 3,200,000 ESRD patients and around 678,000 people were living with kidney transplants (Fresenius
Medical Care, 2013). In developing countries, the figures vary from less than 100 per million in sub-Saharan Africa and India to about 330 per million in Jordan, 360 per million in Iran, and more than 600per million in Saudi Arabia (MahdaviMazdeh, 2007).

Hemodialysis is the most common form of renal replacement therapy (smith, 2013). Hemodialysis elderly patients are commonly affected by a multitude of clinical problems as anemia, mineral and bone disorder (MBD), malnutrition, inflammation, vascular access related infection, and volume management (Castner, 2011). Caring for dialysis elderly and their families can be highly stressful because of the intensity of care required, the nature of $\mathrm{CKD}$ and the elderly patients struggles with dependence (Kallenbach , 2012).

While HD is a lifesaving technique, it cannot substitute a healthy kidney, it taxes the elderly patient and HD related fatigue symptoms considerably disturb patients quality and way of life (Gordon et al.,2011).Fatigue is one of the most public (60-97\%) complications which hemodialysis elderly patients are confronted with. Although the need to find and evaluate this real problem, which its source remains unknown for older adults receiving dialysis, is vital to patient health and quality outcomes (Horigan, 2012). it is noticed by health providers as something that cannot be changed and as a part of the disease course (Bonner, 2008), frequently unrecognized, and therefore undertreated. Fatigue is hard to be measured objectively, and is an unpleasant subjective indicator (O'Sullivan, 2007). This might clarify why fatigue has received moderately little attention in the literature of health providers (Bonner, 2010).

Gerontological nurse must teach the elderly patients on hemodialysis the significance of exercise, diet, and healthy 
sleep practices to reduce symptoms of fatigue (Arora and Verrell, 2009). Furthermore, non - medicational interventions such as Yoga, stress management, depression treatment and acupressure are used to reduce fatigue in hemodialysis elderly patients (Jhamb,2008).

Aim

The aim of the present study is to determine the relationship between fatigue and functional status of the elderly patients on hemodialysis.

\section{Materials and Method}

Study design: Descriptive, corelational design was used in this study. Setting: The study was carried out at hemodialysis unit at New Mansoura General Hospital in Mansoura city affiliated to the Ministry of Health.

\section{Subjects}

A purposive sample was used. The subjects of the study included all elderly patients who receiving hemodialysis at hemodialysis unit at the previous setting within three months. There number amounted 122 elderly patients and selected according to the following criteria: Age 60 years and above, able to communicate, willing to participate in the study and on hemodialysis more than one year.

Study tools: In order to collect the necessary information for the study three tools were used to collect the necessary data.

Tool I: Structured interview questionnaire sheet

It will be developed by the researcher after the literature review and consist of two parts:-

Part (1): Socio demographic characteristics of the elderly such as age, sex, level of education, marital status, occupation before retirement, income. .

Part (2): Health history of elderly patients and medication taken.
Tool II: Katz and Akpom scale (1976) This scale was developed by (Katz and Akpom 1976), originally designed to assess the degree of dependency in performing activities of daily living(ADL). This scale was translated into Arabic and used by (Hallaj, 2007) and was tested for validity and reliability by (Magdi, 2013). The scale include six activities of daily living namely, grooming, toileting, eating, dressing, bathing and mobility. The activities of daily living are measured and scored according to the individuals actual performance. They are categorized into three levels of dependency: independent, partially dependent and totally dependent. A score from one to three was designed to each level of dependency, which one indicates that the person is independent in performing the activities, two indicates that the person perform the activity with assistance, while a score of three indicated that the person is totally dependent. A score of 6 is assigned for those who are partially dependent, while a score from 13 to 18 is assigned for those who are totally dependent .

Tool III: Lawton and Brody scale (1969) This scale was developed by (Lawton and Brody1969), originally designed to assess the degree of assistance needed in performing instrumental activities of daily living(IADL). This scale was translated into Arabic and used by (Hallaj, 2007) and was tested for validity and reliability by (Magdi, 2013). The scale includes eight items: ability to use the telephone, go shopping, food preparation, housekeeping, laundry, transportation, responsibility for own medication and ability to handle finances. The maximum score was 16 for females and 10 for males. The score achieved by the older adults is calculated as a percentage from the maximum score of his category representing $100 \%$. The total degree of the elderly performance is categorized into 
three levels of dependency: independent, partially dependent and totally dependent. A score of $>75 \%$ is assigned for those who are independent, a score from $25 \%$ to less than $75 \%$ is assigned for those who are partially dependent, while a score from zero to less than $25 \%$ is gained by those who are totally dependent.

\section{Tool IV: The Multidimensional Fatigue Inventory Scale (MFI-20)}

It was developed by Smet et al.,(1995). It is originally designed to measure five aspects of fatigue. It was translated into Arabic and validated by (Haggag and Soliman,1997). The scale includes five subscales: general fatigue, mental fatigue, physical fatigue, reduced activity and reduced motivation. The total items were 20 items and has even proportion of positively and negatively worded items. The score achieved by Five points likert scale. The subscale scores ranged from 4-20. The total fatigue score are ranged from 20-100. Higher scores indicate a higher level of fatigue.

\section{Method}

1. Official approval for conducting the study was obtained from the Faculty of Nursing to the director of New Mansoura General Hospital to carry out the study.

2. The director of hemodialysis unit was informed about the purpose of the study and time of data collection.

3. Tool I (Structured interview questionnaire sheet) was developed by the researcher after the reviewing of relevant literature.

4. The Arabic version of the study tools \{ Tool II: Katz and Akpom scale (1976) , Tool III: Lawton and Brody scale(1969) were used and were validated by (Magdi F, 2013) and
Tool IV: The Multidimensional Fatigue Inventory Scale (MFI-20) was validated by (Haggag and Soliman,1997). The reliability was assured by spearman correlation Coefficient $r$ were $r=0.88, r=0.96$ and .70 respectively.

5. A pilot study was carried out on $10 \%$ $(\mathrm{N}=12)$ of elderly patients at New Mansoura General Hospital hemodialysis unit before starting the data collection to test the feasibility of the tools and to make the necessary modifications. The elders who included in the pilot study were excluded from the study sample.

6. Each elderly patient was interviewed individually on hemodialysis unit during and after the session of hemodialysis to collect the necessary data using the study tools.

\section{Ethical consideration}

- The verbal informed consent was obtained from all participants after explaining the purpose of the study.

- Privacy of the subjects and confidentiality and anonymity of the collected data was assured throughout the study. Study subjects were informed about their rights to withdrawn from the study at any time.

\section{Statistical analysis}

Data were analyzed using the statistical package of social science -SPSS $\mid$ software version 16.0 The quantitative data were presented as numbers, percentages. The $\mathrm{P}$ value of $<0.05$ indicate a significant result while, $\mathrm{P}$ value $>0.05$ indicates a nonsignificant result.

\section{Results}


RELATIONSHIP BETWEEN FATIGUE AND FUNCTIONAL etc ...

Table (1): Distribution of the studied elderly according to their Socio demographic characteristics

\begin{tabular}{|c|c|c|}
\hline Items & $\mathrm{N}=110$ & $\%$ \\
\hline 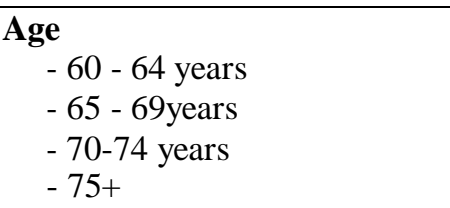 & $\begin{array}{l}66 \\
26 \\
13 \\
5\end{array}$ & $\begin{array}{c}60.0 \\
23.6 \\
11.8 \\
4.6\end{array}$ \\
\hline $\begin{array}{l}\text { Sex } \\
\quad \text { - Male } \\
\text { - Female }\end{array}$ & $\begin{array}{l}60 \\
50\end{array}$ & $\begin{array}{l}54.5 \\
45.5\end{array}$ \\
\hline $\begin{array}{l}\text { Residence } \\
\text { - Rural } \\
\text { - Urban }\end{array}$ & $\begin{array}{l}64 \\
46\end{array}$ & $\begin{array}{l}58.2 \\
41.8\end{array}$ \\
\hline $\begin{array}{l}\text { Marital status } \\
\text { - Married } \\
\text { - Widow } \\
\text { - Divorced } \\
\text { - Single }\end{array}$ & $\begin{array}{l}70 \\
28 \\
10 \\
2\end{array}$ & $\begin{array}{c}63.6 \\
25.5 \\
9.1 \\
1.8\end{array}$ \\
\hline $\begin{array}{l}\text { Educational level } \\
\text { - Illiterate } \\
\text { - Read \& write } \\
\text { - Medium level } \\
\text { - University } \\
\text { - Post graduate }\end{array}$ & $\begin{array}{c}46 \\
33 \\
20 \\
10 \\
1\end{array}$ & $\begin{array}{l}41.8 \\
30.0 \\
18.2 \\
9.1 \\
0.9\end{array}$ \\
\hline $\begin{array}{l}\text { Working before retirement } \\
\text { - Non stressful work } \\
\text { - Doesn't work } \\
\text { - Stressful work }\end{array}$ & $\begin{array}{l}59 \\
41 \\
10\end{array}$ & $\begin{array}{c}53.6 \\
37.3 \\
9.1\end{array}$ \\
\hline $\begin{array}{l}\text { Living condition } \\
\text { - Partner } \\
\text { - Alone } \\
\text { - Offspring \& relatives }\end{array}$ & $\begin{array}{l}64 \\
24 \\
22\end{array}$ & $\begin{array}{l}58.2 \\
21.8 \\
20.0\end{array}$ \\
\hline $\begin{array}{l}\text { Income } \\
\text { - Enough } \\
\text { - Not enough }\end{array}$ & $\begin{array}{l}69 \\
41\end{array}$ & $\begin{array}{l}62.7 \\
37.7\end{array}$ \\
\hline
\end{tabular}

This table describes socio hemodialysis patients is male and slightly demographic characteristics of elderly less than three fifths (58.2\%) of them live hemodialysis patients. This table shows in rural areas. By looking to marital status that about two thirds $(60 \%)$ of statistics the researcher find that slightly hemodialysis elderly patients age is more than $63.6 \%$ of hemodialysis elderly between 60 to less than 65 years old and, patients are married while, one quarter of slightly less than one fifth $(23.6 \%)$ of them them are widow. Moreover, two fifths age between 65 to less than 70 years old, $(41.8 \%)$ of them are illiterate and $30 \%$ of and about (16.4\%) elderly patients age 70 them read and write. According nature of years and above. According hemodialysis work before retirement the table shows patients gender the table shows that that about $53.6 \%$ of patients were working slightly more than one half $(54.5 \%)$ of non stressful jobs and more than $37.3 \%$ of 
them had no work. Moreover,58.2\% of them live with his/ her partner while $21.8 \%$ live alone and more than three fifths $(62.7 \%)$ had enough income.

Table (2): Distribution of the studied elderly according to their medical history and medications consumed

\begin{tabular}{|c|c|c|}
\hline Items & $\mathrm{N}=110$ & $\%$ \\
\hline $\begin{array}{l}\text { Diagnosis } \\
\quad \text { - ESRD* undergoing hemodialysis }\end{array}$ & 110 & 100 \\
\hline $\begin{array}{l}\text { Cause of renal failure } \\
\text { - Hypertension } \\
\text { - Drugs } \\
\text { - Diabetes mellitus } \\
\text { - Diabetes mellitus \& Hypertension }\end{array}$ & $\begin{array}{l}49 \\
28 \\
17 \\
16\end{array}$ & $\begin{array}{l}44.5 \\
25.5 \\
15.5 \\
14.5\end{array}$ \\
\hline $\begin{array}{l}\text { Onset of disease } \\
\text { - More than } 1 \text { year }\end{array}$ & 110 & 100 \\
\hline $\begin{array}{l}\text { Starting hemodialysis } \\
\quad-1-2 \text { years } \\
\text { - } 2 \text { - } 5 \text { years } \\
\text { - More than } 5 \text { years }\end{array}$ & $\begin{array}{l}20 \\
30 \\
60 \\
\end{array}$ & $\begin{array}{l}18.2 \\
27.3 \\
54.5\end{array}$ \\
\hline $\begin{array}{l}\text { Number of hemodialysis sessions } \\
\text { - Three } \\
\text { - Two } \\
\text { - One }\end{array}$ & $\begin{array}{c}102 \\
6 \\
2 \\
\end{array}$ & $\begin{array}{c}92.7 \\
5.5 \\
1.8\end{array}$ \\
\hline $\begin{array}{l}\text { Presence of other diseases } \\
\text { - Yes } \\
\text { - No }\end{array}$ & $\begin{array}{l}78 \\
32\end{array}$ & $\begin{array}{l}70.9 \\
29.1\end{array}$ \\
\hline $\begin{array}{l}\text { If yes (type of diseases) } \\
\text { - Hypertension } \\
\text { - Diabetes mellitus } \\
\text { - Hypertension \& Diabetes mellitus }\end{array}$ & $\begin{array}{c}(\mathrm{N}=78) \\
54 \\
12 \\
12\end{array}$ & $\begin{array}{l}49.1 \\
10.9 \\
10.9\end{array}$ \\
\hline $\begin{array}{l}\text { Taking drugs with hemodialysis } \\
\text { - Yes } \\
\text { - No }\end{array}$ & $\begin{array}{l}91 \\
19\end{array}$ & $\begin{array}{l}82.7 \\
17.3\end{array}$ \\
\hline $\begin{array}{l}\text { Compliance with medications } \\
\text { According doctor order } \\
\text { - When need } \\
\text { - Change dose } \\
\text { - Don't take drugs }\end{array}$ & $\begin{array}{c}75 \\
19 \\
8 \\
8\end{array}$ & $\begin{array}{l}68.2 \\
17.3 \\
7.3 \\
7.3\end{array}$ \\
\hline $\begin{array}{l}\text { Type of drugs taken } \\
\text { - Vitamins } \\
\text { - GIT } \\
\text { - Respiratory } \\
\text { - Rheumatism }\end{array}$ & $\begin{array}{c}72 \\
34 \\
1 \\
3\end{array}$ & $\begin{array}{c}65.5 \\
30.9 \\
0.9 \\
2.7\end{array}$ \\
\hline $\begin{array}{l}\text { This table describe the medical } \\
\text { history of the studied hemodialysis elderly } \\
\text { patients is show that all elderly included in } \\
\text { the study }(100 \%) \text { diagnosed with ESRD. } \\
\text { Slightly less than one half ( } 44.5 \% \text { ) caused by } \\
\text { hypertension. While, } 25.5 \% \text { caused by }\end{array}$ & \multicolumn{2}{|c|}{$\begin{array}{l}\text { drugs. This table shows that all elderly } \\
\text { hemodialysis patients included in this study } \\
\text { had discovered renal failure disease more } \\
\text { than one year, more than } 54.5 \% \text { started } \\
\text { hemodialysis more than five years ago and } \\
\text { the majority of them }(92.7 \%) \text { take three }\end{array}$} \\
\hline
\end{tabular}


hemodialysis sessions per week. Moreover, $70.9 \%$ of elderly patients suffering from other diseases, about one half $(49.1 \%)$ have hypertension with ESRD. More than four fifth $(82.7 \%)$ of hemodialysis elderly taking drugs with hemodialysis. More than two thirds $(68.2 \%)$ of elderly hemodialysis patients are taking their medications according to doctor order. $65.5 \%$ of elderly hemodialysis patients take vitamins while, $30.9 \%$ of them take drugs for GIT problems.

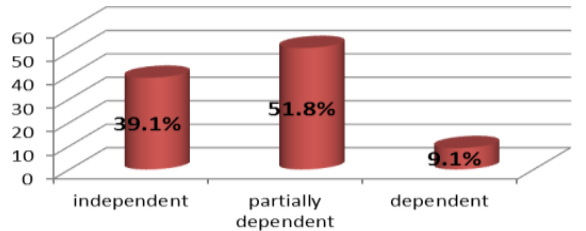

Figure (1): Distribution of the studied elderly according to their level of dependency (ADLs)

This figure describe level of dependency (ADLs) of the studied elderly patients on hemodialysis according to katz and Akpom scale. The figure illustrates that about one half $(51.8 \%)$ of elderly hemodialysis patients are partially dependent on others in their ADLs, while slightly two fifth $(39.1 \%)$ depend on themselves in their ADLs and (9.1\%) are totally dependent on others.

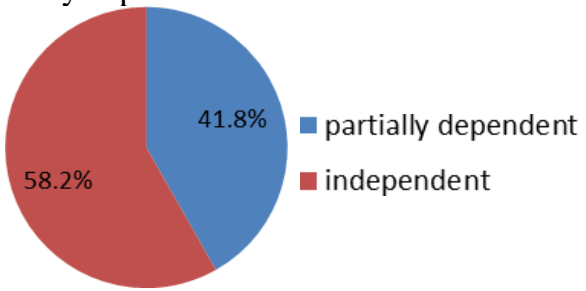

Figure (2): Distribution of the studied elderly according to their level of dependency (IADLs)

Table (3): Correlation between fatigue and Functional status of the studied elderly

\begin{tabular}{|c|c|c|c|c|c|c|}
\hline \multirow{3}{*}{ Variables } & \multicolumn{4}{|c|}{ Functional status } & \multirow{2}{*}{\multicolumn{2}{|c|}{ Fatigue }} \\
\hline & \multicolumn{2}{|c|}{ ADLs } & \multicolumn{2}{|c|}{ IADLs } & & \\
\hline & $\mathbf{r}$ & $P$ value & $\mathbf{r}$ & $P$ value & $\mathbf{r}$ & P value \\
\hline ADLs & ....... & $\ldots \ldots$ & 0.524 & $0.000 *$ & 0.409 & $0.000 *$ \\
\hline IADLs & 0.524 & $0.000 *$ & $\ldots \ldots$ & $\ldots \ldots$ & 0.297 & $0.002 *$ \\
\hline Fatigue & 0.409 & $0.000^{*}$ & 0.297 & $0.002 *$ & ....... & ...... \\
\hline
\end{tabular}

dependency of hemodialysis elderly patients (IADLs) according to Lawton and Brody scale. The figure shows that slightly less than three fifth $(58.2 \%)$ are independent, while two fifth $(41.8 \%)$ of them are partially dependent on others in their IADLs.

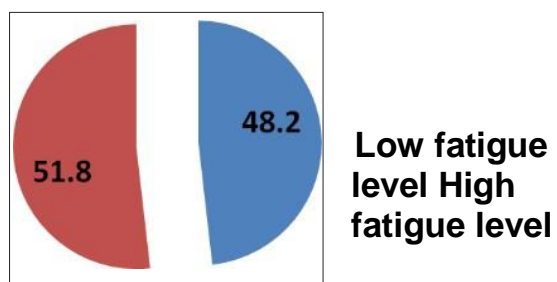

Figure (3): Distribution of the studied elderly according to fatigue levels

This figure shows that about half of study sample $(51.8 \%)$ have high level of fatigue and $(48.2 \%)$ have low level of fatigue than mean score of the studied elderly hemodialysis patients in this sample. 
This table shows a significant correlations between ADLs and both IADLS and Fatigue. Also, there is a significant correlation between IADLs and Fatigue.

\section{Discussion}

The perception of fatigue in ESRD is difficult to be defined. HD elderly patients may express fatigue in different actions (weakness, lack of energy, and tiredness). There are two forms of fatigue: mental (including emotional and cognitive) and somatic (including insomnia, lack of energy and weakness) (Hardy and Studenski, 2010).

In the present study we found that about two thirds $(60 \%)$ of hemodialysis elderly patients age is between 60 to less than 65 years old. This was in accordance with a study done in Japan by (Liu et al.,2015) who reported that the average age of dialysis patients was almost 67 years in 2013, with an increase in the number of dialysis patients being largely due to the growth in the fraction of patients who were $>65$ years of age. whereas, in Europe, the mean age was 62.0 years (Pippias et al.,2015). This finding does not agree with (Zahran ,2011) who reported that, the mean age of the studied HD patients was 52 years. In addition (Abdallah et al., 2014) found that the mean age of the studied HD patients was 52.5 years and reported that, increasing mean age of ESRD patients in Egypt reflects the improvement of healthcare.

According to gender, $54.5 \%$ of elderly patients were males. That is in line with a study done by (Rabie, 2015) who found that more than half of the patients were men may be as a result of smoking, HTN and prostatic enlargement.

In relation to area of residence, the recent study shows that the majority of elderly patients lives in rural areas that is supported by (Stanifer et al.,2014) who found that chronic renal disease seems to be more prevalent in rural regions compared to urban settings. However, (EL Shahed et al.,2013) mentioned that, around two-thirds of their studied HD patients were living in an urban areas.

Regarding educational level, about two fifth of elderly patients are illiterate that is in line with (Bahgat, 2013) who described that more than half of the studied subjects in her study were illiterate. This is not in line with (Abd El Hafeez,2010) who reported that about one third of the HD patients had secondary educational level.

According to marital status, slightly more than three fifth in our study are married. Married patients might receive more social support from their families . This conclusions agrees with (Elsebai et al.,2011) who found that, more than two thirds of the HD patients were married. Regarding economic status, about two third $(62.7 \%)$ had enough income this is not agreed with (Abd El Hafeez ,2014) who stated that, more than half of the hemodialysis patients experienced financial complications.

According to the cause of renal failure, slightly less than one half of hemodialysis in elderly patients caused by hypertension, This result is supported by a study done in Menoufia governorate by (Zahran, 2011) who stated that the main known cause of ESRD was hypertension (34.8\%) followed by diabetes $(16.6 \%)$. It may be related age related changes in cardiovascular system that increase risk for hypertension in older age. However, the present study findings are disagree with various reports from the United States Renal Data System (USRDS) who showed that DM was the leading cause of ESRD. (USRDS ,2013) \& (USRDS ,2012). while (Henrique et al.,2010) stated that the most frequent cause of $\mathrm{CKD}$ was chronic glomerulonephritis. 
In relation to duration of management by hemodialysis, it was found that, more than $60 \%$ of the elderly patients were undergoing $\mathrm{HD}$ since more than five years, as well as above $30 \%$ were undergoing $\mathrm{HD}$ from $2-5$ years. This finding is congruent with (Al Eissa et al .2010) who found that, more than half of the patients were on dialysis for more than three years.

In relation to numbers of $\mathrm{HD}$ sessions per week, it was detected that the majority of elderly patients were organized for $\mathrm{HD}$ three sessions per week. This finding agrees with (El Ariny ,2014) who found that, the majority of hemodialysis patients had three sessions per week. Moreover, the results of this study presented that, the majority of patients had four hours per session. This finding is in line with (Mottahedian et al.,2009) who found that the majority of dialysis sessions lasted for 4 hours.

In relation to co-morbidities with hemodialysis, the majority of hemodialysis elderly have HTN in this study, It might be because of complications of chronic kidney disease and hemodialysis or might be a cause of renal failure. This is congruent with (Karadag et al .,2013) who reported that, more than three quarters of HD patients had other chronic diseases besides chronic renal failure.

In the present study, we figured out that more than two thirds $(68.2 \%)$ of elderly hemodialysis patients compliant with medications according to doctor order. It may be that older patients may have more organized lifestyle that accommodates the demands of the treatment regimen and presence of family members who cares for compliance with therapeutic regimen. That is supported by (Kim and Evangelista ,2010) who indicated that older age was associated with higher compliances to fluid restriction and medication prescription.
With the aging of populations, impairment in the ADLs, IADLs, or both affect up to $50 \%$ of elderly patients on chronic hemodialysis (Kutner et al., 2014). Our results described the level of dependency (ADLs) of the studied elderly patients on hemodialysis. We showed that about one half (51.8\%)of elderly hemodialysis patients are partially dependent on others in their ADLs, and $(9.1 \%)$ are totally dependent on others. And we found that two fifth $(41.8 \%)$ of elderly patients are partially dependent on others in their IADLs. This is agreed with (Quinn, 2011) \& (Vieira et al.,2013) who concluded that older people with acute and chronic problems adversely affect their functional abilities. And (Bahgat, 2013) stated that about half of the sample requires care takers in the first and second week of assessment.

All patients with CKD revealed fatigue as a most noticeable clinical symptoms (Mahrova and Svagrova

,2013) . Besides fatigue affects not only day life but also disturbed daily self-care activities, emotional status, and therefore the QoL (Cronin and Henrich ,2013). In this study about half of study sample have high level of fatigue, it may be due to Aging changes and anemia in elderly on hemodialysis. this result is congruent with (Dadgari et al .,2015) study who concluded that dialysis elderly patients have higher fatigue score than non-dialysis patients.

This study found significant correlations between fatigue and functional status . according to (Bahgat, 2013) there was a significant negative correlation was found between degree of fatigue and of daily living activities. So when the fatigue increases the daily living activities decreases and when the fatigue decreases the daily living activities increases. (Kazemi, 2011) agrees with this findings and reported that there was 
negative correlation between fatigue and daily living activities.

Fatigue management consist of pharmacologic and life style modifications. The first technique include (vitamin C, L-carnitine, and different medications as well as erythropoietin to overcome anemia). Second technique include (relaxation as yoga, exercise, acupuncture, electric stimulation, and dialysis) (Mahrova and Svagrova , 2013).Interestingly, Exercise relieve deterioration produced by aging process, diseases, and inactive lifestyle (Gordon et al., 2011).

Conclusion and recommendations:

It can be concluded that the frequency of fatigue is high among hemodialysis elderly patients and the majority of hemodialysis elderly aged 60 to less 65 years old. All hemodialysis elderly diagnosed with ESRD and the majority of them started hemodialysis more than five years ago. The majority of the studied subjects had high level of fatigue while two fifth were independent in ADLs and two fifth were partially dependent in their IADLs. A statistically significant correlation between fatigue and functional status of the studied subjects.

Based on the results of the present study, the following recommendations are suggested:

1. Development \& Implementation of Health educational programs for newly elders on hemodialysis about hemodialysis process and fatigue and its management.

2. Development of health educational program for nurses \& health care personnel about fatigue in elderly and its effect on quality of life.

3. Designing \& Developed illustrated booklet about interventions that can be tailored to meet individual needs should be available and distributed for each elderly patient admitted to hemodialysis unit.

\section{References}

1. Abd El-Hafeez, N. (2010): Concerns of patients with end stage renal disease undergoing hemodialysis. Unpublished Master Thesis. Faculty of Nursing, Alexandria University.

2. Abd El-Hafeez, N. (2014): "The effect of implementing an instructional module on controlling adverse events of hemodialysis among patients with chronic renal failure." Unpublished Doctoral Thesis. Faculty of Nursing, Alexandria University.

3. Ahmed A, Allam M, Habil E, Metwally A, Ibrahiem N, Radwan M, El Gaafary M, Afifi A, Gadallah M.( 2010): Development of practice guidelines for hemodialysis in Egypt. Indian Journal of Nephrology; 20(4): 193. Available at: www.ncbi.nlm.nih.gov. Accessed Nov 3, 2016.

4. Al Eissa M, Al Sulaiman M, Jondeby M, Karkar A, Barahmein M, Shaheen F, Al Sayyari A. (2010): Factors affecting hemodialysis patients" satisfaction with their dialysis therapy. International Journal of Nephrology; 20(10): 1-2. Available at: https://www.hindawi. com. Accessed Jan 25, 2017.

5. Arora P, Verrell M ( 2009): Chronic kidney disease treatment \& management. Available at: http://emedicine.medscape.com Accessed Oct 11,2015.

6. Bahgat $Z$ (2013): The Effect of Fatigue on Daily Living Activities for Adults Undergoing Hemodialysis. Published Master thesis. Faculty of Nursing. Tanta university.

7. Barsoum, R. S. (2013): "Burden of chronic kidney disease: North Africa." Kidney International Supplements 3(2): 164-166. 
8. Bonner, A., Wellard S, Caltabiano M. (2008): "Levels of fatigue in people with ESRD living in far North Queensland." Journal of Clinical Nursing 17(1): 90-98.

9. Bonner, A., Wellard S, Caltabiano M. (2010): "The impact of fatigue on daily activity in people with chronic kidney disease." Journal of Clinical Nursing 19(21-22): 3006-3015.

10. Castner, D. (2011): "Management of patients on hemodialysis before, during, and after hospitalization: challenges and suggestions for improvements." Nephrology Nursing Journal 38(4): 319-320.

11. Clegg A, Young J, Iliffe S, Rikkert MO, Rockwood K.( 2013): Frailty in elderly people. Lancet ;381:752-

62. Available at: https://www.ncbi.nlm.nih.gov. Accessed Nov 20, 2016.

12. Cohen, G. and W. Hörl (2012): "Immune Dysfunction in UremiaAn Update." Toxins 4(12): 962-990. Available at: http://www.ncbi.nlm.nih.gov. Accessed Dec 20, 2016.

13. Collins, A. J., Foley R, Herzog C et al. (2008): "Excerpts from the United States Renal Data System 2007 annual data report." Am J Kidney Dis 51(1 Suppl 1): S1-320. Available at: http://www.ajkd.org. Accessed Jan 10, 2016.

14. Cronin RE, Henrich WL. (2013): $\mathrm{Kt} / \mathrm{V}$ and the adequacy of hemodialysis. Available from: http://www.uptodate.com. kt-v-andthe-adequacy-of-hemodialysis.
15. Dadgari, A., Dadvar L, EslamPanah H (2015): "Multidimensional fatigue syndrome and dialysis adequacy among elderly patients under hemodialysis treatment." International Journal of Health Studies 1(2): Page: 5-8.

ijhs.shmu.ac.ir. Accecced Sep 7, 2016.

16. El Shahed A, Sharf S, El Esbaee H, Roshdy M. (2013):"Hemoglobin Level, Associated Co-Morbidities and Quality of Life among Patients Undergoing Hemodialysis at One of the University Hospitals in Cairo Governorate." World Applied Sciences Journal 23(1): 29-36.

17. El Ariny, M. (2014): "The annual data focused on causes of hospitalization in the hemodialysis population." Unpublished Master Thesis. Faculty of Medicine, Ain Shams University.

18. El Fattah Abdallah M, Baki A, Abdel Hakim S, Kamel C (2014): "Epidemiological study of end stage renal disease at Ain Shams University Hospital. A five year retrospective study." Life Science Journal 11(12): 1065.

19. Elithy W, Soliman H (1997) : The Arabic Version of Multidimensional Fatigue Inventory : Reliability, Validity and findings in Three Groups. Egypt.J. Psychiat.20: 1 .

Available at: psychiatry-researcheg.com. Accessed July 21, 2015.

20. Fresenius Medical Care (2012): ESRD patients in 2011: A global perspective. Fresenius Medical Deutschland $\mathrm{GmbH}$; 2012. Available at: http: //www.visionfmc.com. Accessed Jul 7, 2015. 
21. Gordon P, Doyle J, Johansen K. (2011): Postdialysis fatigue is associated with sedentary behavior. Clinical Nephrology; 75(5): 426-433. available

at: https://www.researchgate. net. Accessed Oct 6, 2016.

22. Hallaj F (2007): Activity patterns of Residents in Elderly Homes. Unpublished Master Thesis. Faculty of Nursing. University of Alexandria.

23. Hardy, S. E. and S. A. Studenski (2010); "Qualities of Fatigue and Associated Chronic Conditions Among Older Adults." Journal of Pain and Symptom Management 39(6): 1033-1042.

24. Headley, C. (2011): Acute kidney injury and chronic kidney disease. Medical Surgical Nursing: Assessment and management of clinical problems. S. Lewis, S. Dirksen, M. Heitkemper, L. Bucher and I. Camera. United States of America, Elsevier 2: 1170-1174.

25. Henrique DM, Reboredo Mde M, Chaoubah A, Paula RB (2010): "Aerobic exercise improves physical capacity in patients under chronic hemodialysis." Arquivos brasileiros de cardiologia 94(6): 823-828. available at: www.scielo.br. Accessed Dec 12, 2016.

26. Holley, J. L. (2011): "Age, eGFR, and CKD Complications." Clinical Journal of the American Society of Nephrology 6(12): 2729-2731.

27. Horigan A, Rocchiccioli J, Trimm D. (2012): "Dialysis and fatigue: implications for nurses-a case study analysis." Medsurg nursing: official journal of the Academy of MedicalSurgical Nurses 21(3): 158-163. Available at: https://www.ncbi.nlm.nih.gov. Accessed Aug 4, 2016.
28. Jhamb M, Weisbord S, Steel J, Unruh $M$ (2008): "Fatigue in Patients Receiving Maintenance Dialysis: A Review of Definitions, Measures, and Contributing Factors." American Journal of Kidney Diseases 52(2): 353-365.

29. Kallenbach, J. Z. (2012): Review of hemodialysis for nurses and dialysis personnel. USA, Elsevier Health Sciences.

30. Karadag E, Kilic SP, Metin O. (2013): "Relationship between fatigue and social support in hemodialysis patients." Nursing \& Health Sciences 15(2): 164-171. Available at: https://www.ncbi.nlm.nih.gov. Accessed Dec 3, 2016.

31. Katz S, Akpom C (1976): Index of ADL : A standardized measure of biological and psychological function. International $\mathbf{J}$ of Health Science, 6(6):123-40. Available at : home.uchicago.edu. Accessed Oct 6, 2015.

32. Kazemi M, Nasrabadi A, Hasanpour M, Hassankhani H \& Mills J. (2011): "Experience of Iranian persons receiving hemodialysis: A descriptive, exploratory study." Nursing \& Health Sciences 13(1): 88-93. Available at: https://www.researchgate.net. Accessed Feb 11, 2017.

33. Kim Y, Evangelista LS (2010): Relationship between illness perceptions, treatment adherence, and clinical outcomes in patients on maintenance hemodialysis. Nephrol Nurs J 37(3): 271-280.

34. Kutner NG, Zhang R, Allman RM, Bowling CB. (2014): Correlates of ADL difficulty in a large hemodialysis cohort. Hemodial Int ;18:70-7. available at: https://www.ncbi.nlm.nih. gov. Accessed Feb 5, 2017. 
RELATIONSHIP BETWEEN FATIGUE AND FUNCTIONAL etc ...

35. Kurella, M. (2007). "Octogenarians and Nonagenarians Starting Dialysis in the United States." Annals of Internal Medicine 146(3): 177-183.

36. Larson K, Houglum M, Axley B, Dinwiddie L, Smith K, Twaddell J. (2013): End stage renal disease briefing book for state and federal policymakers: a guide to kidney disease awareness and education. Pitman, NJ: American Nephrology Nurses Association; 4. Available at: https://www.annanurse.org. Accessed Sep 1, 2016.

37. Lawton H , Brody E (1969): Assessment of older people: Self maintaining and instrumental activities of daily living. Gerontologist.1(9):179-86. Available at : www.eurohex.eu. Accessed Sep 11, 2015.

38. Levey AS, Stevens LA, Coresh J. (2009): "Conceptual Model of CKD: Applications and Implications." American Journal of Kidney Diseases 53(3): S4-S16. Available at: https://www.ncbi.nlm.nih.gov.

Accessed Apr 13, 2016.

39. Liu FX, Rutherford P, SmoyerTomic K, et al. (2015): "A global overview of renal registries: a systematic review." BMC Nephrology 16(1). Available at: http://www.sciencedirect. com. Accessed Jan 13, 2017.

40. Magdi F (2013): Relationship Between Presence of Anemia And The Physical Performance of The Elderly Patients Attending The Outpatient Clinics Hospital In Mansoura City. Published Master Thesis. Faculty of Nursing. University of Alexandria.

41. Mahdavi-Mazdeh M, Heidary Rouchi A, Norouzi S, Aghighi M, Rajolani H, Ahrabi S. (2007) :Renal replacement therapy in Iran. Urol $\mathrm{J} ; 4: 66-70$.
42. Mahrova, A. and K. Svagrov (2013): Exercise Therapy Additional Tool for Managing Physical and Psychological Problems on Hemodialysis. Hemodialysis, InTech. Available at : https://www.intechopen.com.

43. Mottahedian T, Najafi M, Samiey S, Einollahi B, Babaei G. (2009): "Effect of programmed nursing care in prevention of hemodialysis complications." Journal of Critical Care Nursing 2(2): 55-59. Available at: www.sid.ir. Accessed Dec 13, 2016.

44. O'Sullivan, D. and G. McCarthy (2007): "An exploration of the relationship between fatigue and physical functioning in patients with end stage renal disease receiving haemodialysis." Journal of Clinical Nursing 16(11c): 276-284.

45. Ozkan, G. and S. Ulusoy (2011): Acute Complications of Hemodialysis. Technical Problems in Patients on Hemodialysis, InTech: 269-278.

46. Quinn T, Stott D and Ellis G (2011): Functional assessment in older people. BM Journals ; 343: 298 468. available at: www.bmj.com. Accessed Dec 13, 2016.

47. Rabie E (2015): Patients' Satisfaction With Nursing Care In Hemodialysis Units. Un published master thesis. Faculty of Nursing. Alexandria university.

48. Shaker $T$ (2015): Effect of Pre Established Nursing Care Standards on Knowledge and Performance of Nurses Working at Hemodialysis Unit of International Mansoura Hospital. Master thesis, Faculty of Nursing. Mansoura university. 
49. Smets E, Garsen B, Bonke B, Haes J (1995) :The multidimensional fatigue inventory. Pschometric qualities of an instrument to assess fatigue. J Pschoom. Res., 5: 315-

325. Available at http://www.ncbi.nlm.nih.gov.

Accessed Sep 15, 2015.

50. Smith, A. L. (2013): "End Stage Renal Disease and Hypertension: Connecting the Disconnect with Spironolactone." BCPS. Available at: https://www.utexas.edu. Accessed Aug 10, 2016.

51. Stanifer JW, Jing B, Tolan S, Helmke N, Mukerjee R, Naicker S, et al. (2014): "The epidemiology of chronic kidney disease in subSaharan Africa: a systematic review and meta-analysis." The Lancet Global Health 2(3): e174-e181. Available at: http://www.thelancet.com. Accessed Feb 3, 2017.

52. Stevens LA, Viswanathan G, Weiner DE. (2010): "Chronic Kidney Disease and End-Stage Renal Disease in the Elderly Population: Current Prevalence, Future Projections, and Clinical Significance." Advances in Chronic Kidney Disease 17(4): 293-301. Available at: www.sciencedirect.com. Accessed Jan 6, 2016.

53. Thomas, R. Kanso, A. Sedor, J. (2008): "Chronic Kidney Disease and Its Complications." Primary Care: Clinics in Office Practice 35(2): 329344. Available at: https://www.ncbi.nlm.nih.gov. Accessed Mar 15, 2016.
54. U.S. Renal Data System: USRDS (2012) Annual Data Report: Atlas of End-Stage Renal Disease in the United States, Bethesda, MD, National Institutes of Health, National Institute of Diabetes and Digestive and Kidney Diseases. Available at http://www.usrds.org Accessed May 7th 2016.

55. U.S. Renal Data System: USRDS (2013) Annual Data Report: Atlas of End-Stage Renal Disease in the United States, Bethesda, MD, National Institutes of Health, National Institute of Diabetes and Digestive and Kidney Diseases. Available at: http://www.usrds. org. Accessed May 7th 2016.

56. Vieira $D$, Tibana $R$, Tajra $V$, et al (2013): "Decreased functional capacity and muscle strength in elderly women with metabolic syndrome." Clinical Interventions in Aging 8: 1377-1386. Available at: https://www.ncbi.nlm.nih.gov. Accessed Feb 12, 2017.

57. Zahran, A. (2011): "Epidemiology of hemodialysis patients in Menofia Governorate." Delta region, Egypt. MMJ 24(1): 211-220.

58. Zhang L, Wang F, Wang L, Wang W, Liu B, Liu J, et al.(2012): "Prevalence of chronic kidney disease in China: a cross-sectional survey." The Lancet 379(9818): 815822. Available at: https://www.ncbi.nlm.nih.gov. Accessed Dec 15, 2016. 